\title{
Thermo-hydraulic performance enhancement of solar air heater (SAH) having multiple arcs with gap shaped roughness element on absorber plate
}

\author{
Navneet Kumar Pandey ${ }^{1 *}$, V. K. Bajpai ${ }^{2}$ \\ ${ }^{l}$ Department of Mechanical Engineering, JSS Academy of Technical Education, Noida (UP) - 201301, INDIA \\ ${ }^{2}$ Department of Mechanical Engineering, National Institute of Technology Kurukshetra (Haryana), INDIA \\ *Corresponding author: e-mail: (Navneet Kumar Pandey)nkpandey@jssaten.ac.in, (V. K. Bajpai) vkbajpai@yahoo.com
}

\begin{abstract}
The present paper studies the thermal performance of solar air heater which is artificially roughened by providing multiple arcs with gap shaped roughness element. As thermal efficiency of smooth collector is quite low, hence there is a need to augment heat transfer from the absorbing surface. The experimentation has been carried out for Reynolds number $(R e)$ ranges from 210021000 , relative roughness height $(e / D)$ of 0.044 , relative roughness pitch $(\mathrm{p} / \mathrm{e})$ of 8 , relative gap distance $(d / x)$ range of 0.25 0.85 , relative roughness width $(W / w)$ ranges from 1-7, relative gap width $(g / e)$ range of 0.5-2 and arc angle $(\alpha)$ of $60^{\circ}$. The thermal efficiency is found to be best for relative gap distance $(d / x)$, relative gap width $(g / e)$ and relative roughness width $(W / w)$ values are $0.65,1.0$ and 5 respectively.
\end{abstract}

Keywords: Solar air heater; Nusselt number; thermal efficiency; multiple arcs with gap; roughened

DOI: http://dx.doi.org/10.4314/ijest.v8i1.3

\section{Introduction}

Easy access to a low cost reliable power supply is a prerequisite for the economic development and well-being of all sovereign nation states. The economic activity and development of society would have been very much limited and restrained without the heat and electricity from fossil fuel combustion. Renewable energy is expected to play a crucial role in the quest towards a sustainable society in this century. It has enormous potential to meet the growing energy requirements of the increasing population of the world, while offering sustainable solutions to the global threats of climate change. The eco-friendly nature and free availability of solar energy in abundance are the two factors that have made solar energy favorite among other alternate sources of energy. Solar energy has a potential to fulfill the energy requirements of all human made systems provided technologies are developed to tap the potential of solar energy (Chamoli, 2013). Considerable efforts are being made to develop technologies to tap the great potential of solar energy.

Air is generally used as a heat transferring fluid in many types of energy conversion systems. Solar air heater is a type of heat exchanger where heat has been carried away by air from the heated absorber plate. These find several applications in space heating, seasoning of timber and crop drying. Solar air heaters have been fabricated in variety of designs. They include overlapped, spaced, clear and black glass plates, single smooth metal sheets, flow through stacked screen or mesh, corrugated metal plates, finned metal sheets and others. The air passing beneath the plate or underlying air passage reduces downward heat loss; and one or two covers of glass or transparent plastic provide resistance to upward convection and radiation heat losses.

Solar air heaters, being inherently simple and cheap, are most widely used collection devices. The low value of heat transfer coefficient is generally attributed to the presence of a viscous sub-layer, which can be broken by providing artificial roughness on the heat transferring surface (Kumar, 2010).

The thermal efficiency of solar air heater is generally found to be low because of their low heat transfer capability. In order to make solar air heaters useful the thermal performance needs to be increased by augmenting the heat transfer coefficient. To 
augment the heat transfer coefficient there is a need to make the flow more turbulent. Heat transfer co-efficient enhancement techniques are generally divided in two groups; namely active and passive. The active techniques require external forces, e.g., acoustic, surface vibration or electric field etc. and passive techniques require special surface geometry, i.e. rough and external surface, fluid additives and swirl flow devices (Kumar, 2010). It is for this purpose, artificial roughness has been used. The artificial roughness is creating roughness in the flow passage which will make the flow to be more turbulent. The artificial roughness could be of several shapes such as small diameter wire, V-shaped, wedge shaped ribs etc. (Prasad and Saini, 1988; Varun et al., 2007; Singh et al., 2011; Varun et al., 2008; Bhagoria et al., 2002). Several investigators investigated fully developed flow in solar air heaters duct with small protrusion on the absorber plate (Yadav et al., 2013). It is well known that although the thermal efficiency of a solar air heater can be increased by providing artificial roughness, but it also can result in substantial increase in friction losses and hence greater power requirement from blower or fan. In this work thermal performance has been evaluated for various geometrical parameters of artificially roughened duct. Multiple arcs shaped roughness elements provided with gaps has been used as roughness element under the absorber plate.

Various studies, using different roughness geometries are available in the literature. The geometries include transverse, inclined, arc shape and $\mathrm{V}$-shape. The studies are primarily dedicated to rectangular duct but few have been dedicated to triangular passage also. However, some investigators have worked on solar air heaters using CFD. Studies carried out to compare the CFD simulation with experiments for same conditions and the results are found to be satisfactory. CFD studies help reduce time as compared to experimental studies and have been found to have good agreement with the experimental results.

\section{Details of Experimental Set-Up}

An experimental test facility was designed and fabricated to study the effect of multiple arcs with gap shaped roughness elements on heat transfer and fluid flow characteristics. A line diagram of experimental set up is shown in Figure 1. It consists of an entry section, test section, exit section, transition section (plenum), a flow measuring (orifice plate) and a centrifugal blower with two control valves. A wooden rectangular duct was having a size of $2500 \mathrm{~mm} \times 250 \mathrm{~mm} \times 25 \mathrm{~mm}(\mathrm{~L} \times \mathrm{W} \times \mathrm{H})$ and provided with an entrance section, a test section and an exit section of lengths $900 \mathrm{~mm}, 1000 \mathrm{~mm}$ and $600 \mathrm{~mm}$ respectively as per the recommendations of ASHRAE Standard (1977). An electric heater was fabricated over the asbestos sheet by arranging five loops of nichrome wire in parallel and series combination which is having a size of $1000 \mathrm{~mm} \times 250 \mathrm{~mm}$.

The heat flux in this case varies from $0-1200 \mathrm{~W} / \mathrm{m}^{2}$ with the help of a variac. A mica sheet of $1 \mathrm{~mm}$ thickness was placed over the heater to ensure uniform radiation on the absorber plate. The glass wool was used as insulation inside wooden panel to reduce top loss from the heater. Artificial roughness was created on the underside of plate by pasting soft aluminum wire having a shape of multiple arcs with gap. The pressure drop across the test section was measured using micro-manometer having a least count of $0.01 \mathrm{~mm}$ of water. The temperatures at various locations were measured using calibrated Copper-Constantan thermocouples of 16 SWG. They are connected to digital milli-voltmeter through selector switch to indicate temperature. Line diagram of roughness geometry and locations of thermocouples on the absorber plate is shown in Figures 2 and 3, respectively. Table 1 shows the range of parameters studied.

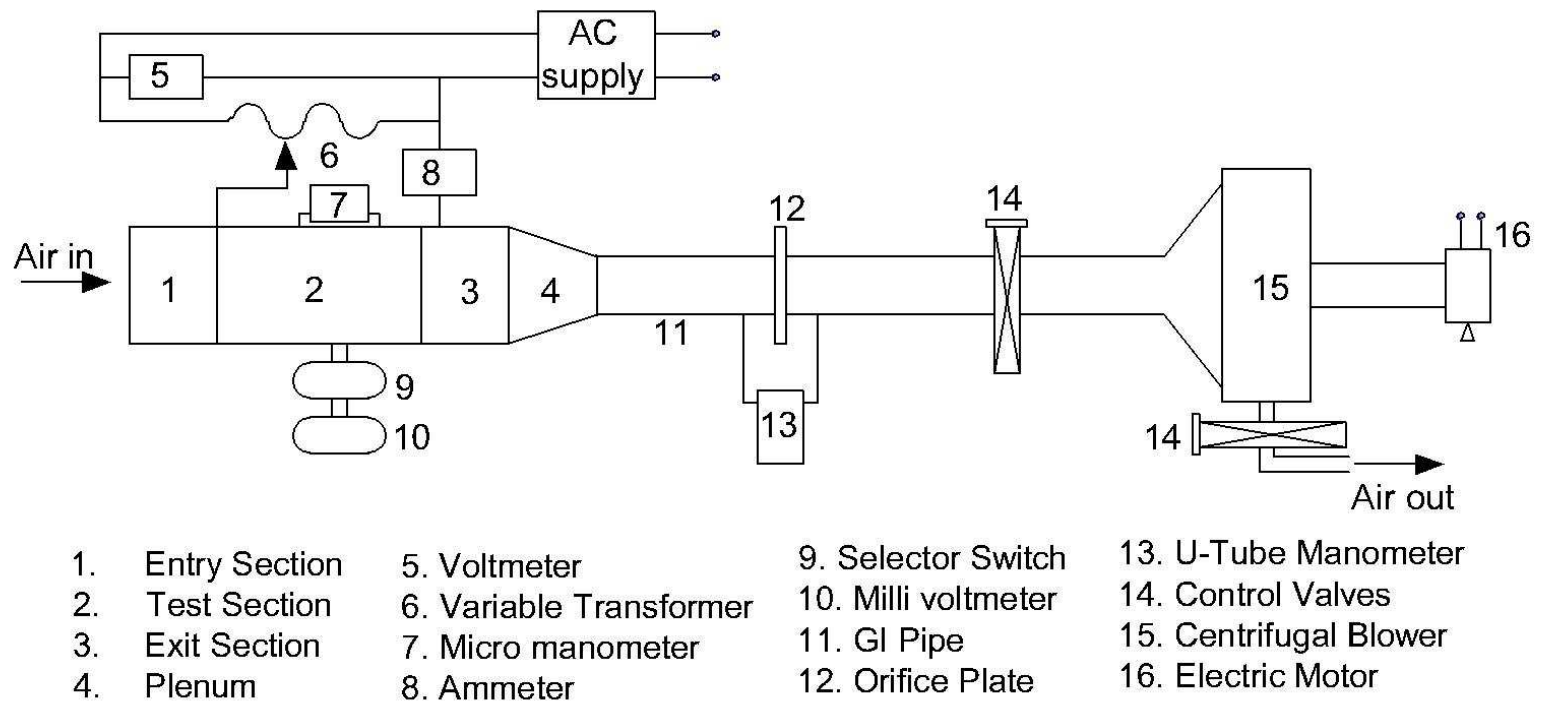

Figure 1: Line diagram of experimental set up 


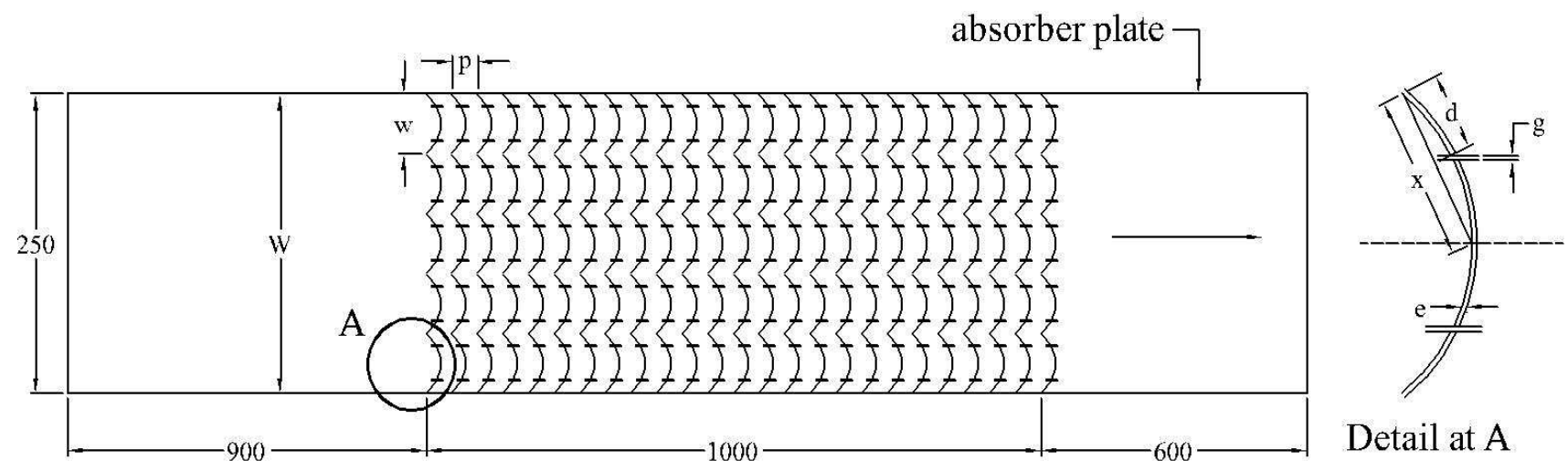

Figure 2: line diagram of roughened absorber plate

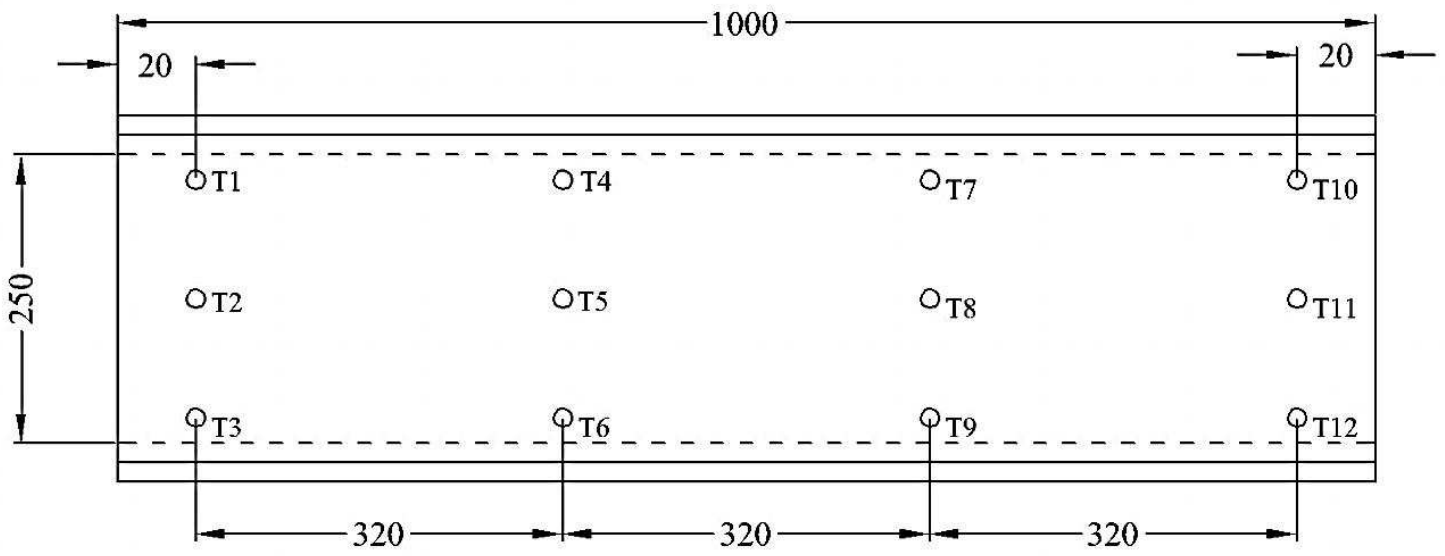

all dimensions are in $\mathrm{mm}$

Figure 3: Locations of thermocouple on absorber plate

Table 1: Values of flow and roughness parameters.

\begin{tabular}{lll}
\hline S. No. & Parameter & Range \\
\hline 1 & Reynolds number $(R e)$ & $2100-21000$ \\
2 & Relative roughness pitch $(p / e)$ & 8 (fixed) \\
3 & Relative roughness height $(e / D)$ & 0.045 (fixed) \\
4 & Arc angle $(\alpha)$ & $60^{\circ}$ (fixed) \\
5 & Relative gap width $(g / e)$ & $0.5-2.0$ \\
6 & Relative gap distance $(d / x)$ & $0.25-0.85$ \\
7 & Aspect ratio $(W / H)$ & 10 (fixed) \\
8 & Relative roughness width $(W / w)$ & $1-7$ \\
\hline
\end{tabular}

\subsection{Experimental Procedure}

The experimental data related to heat transfer and flow friction was collected in accordance with the ASHRAE Standard for testing in open loop flow mode. In this study, various roughness parameters were investigated i.e. relative roughness width (W/w), relative gap distance $(\mathrm{d} / \mathrm{x})$ and relative gap width $(\mathrm{g} / \mathrm{e})$. Before the start of experimentation joints of the duct, pipes and plenum were thoroughly checked with the help of bubbles to ensure that there was no leakage in the entire set up. Seven values of air-flow rates (Reynolds number) were considered for each type of absorber plate at a fixed heating of $1000 \mathrm{~W} / \mathrm{m}^{2}$. The micro-manometer and U-tube manometer were leveled properly with the help of spirit level. Blower was switched on and flow control valves were adjusted to give a set value of mass flow rate of the air through the duct. All the data were recorded under quasi-steady state conditions that were assumed to have been attained when the absorber and outlet air temperatures do not deviate over a period of 5-10 minutes. The following parameters were measured for each set of readings:

(i) Air temperature inside the duct (inlet, outlet).

(ii) Absorber plate temperature at 12 points.

(iii) Pressure drop across the test section

(iv) Mass flow rate of air with the help of orifice meter 


\section{Data Reduction}

The experimental data which was used to calculate heat transfer and pressure drop is collected as per the procedure described in section 2.1. Heat transfer $(\mathrm{Nu})$ was estimated to see the effect of roughness parameters on its thermal performance. The equations used in this section are used to calculate mass flow rate and by using mass flow rate useful heat gain is estimated. After calculating useful heat gain, Nusselt number has been estimated.

$m=C_{d} A_{o} \sqrt{\frac{2 \rho \Delta P_{o}}{1-\beta^{4}}}$

The calibration of orifice-plate was carried out using a standard Pitot tube which gives a value of 0.60 for coefficient of discharge $\left(\mathrm{C}_{\mathrm{d}}\right)$.Where,

$\Delta P_{\mathrm{o}}=9.81 \rho \Delta h_{\mathrm{o}}$

$Q_{u}=m C_{p}\left(t_{o}-t_{i}\right)$

and $\quad h=\frac{Q_{u}}{A_{p}\left(t_{p}-t_{f}\right)}$

where, $A_{p}$ is area of absorber plate, $t_{f}$ and $t_{p}$ are mean values of fluid and absorber plate temperatures, respectively. The Nusselt number $(\mathrm{Nu})$ is calculated by using following relationship.

$N u=\frac{h D}{k}$

For the calculations, air properties were taken corresponding to bulk mean air temperature. The error analysis has been carried out as per the method proposed by Kline and McClintock (1953). For all the roughened plates investigated, the maximum error values for non-dimensional number are given below.

Reynolds Number: $\pm 2.41 \%$

Nusselt Number: $\pm 7.91 \%$

\section{Thermal Performance}

As per recommendations of ASHRAE, thermal efficiency of a solar collector can be expressed by following equation (Varun et al., 2008);

$$
\eta=F_{R}\left[(\tau \alpha)-U_{L}\left(\frac{t_{i}-t_{a}}{I}\right)\right]
$$

The relationship between the collector efficiency factor $\left(\mathrm{F}^{\prime}\right)$ and the heat removal factor $\left(\mathrm{F}_{\mathrm{R}}\right)$ is given as;

$$
\mathrm{F}_{\mathrm{R}}=\frac{\mathrm{mC}_{\mathrm{p}}}{\mathrm{A}_{\mathrm{C}} \mathrm{U}_{\mathrm{L}}}\left[1-\operatorname{Exp}\left(-\mathrm{A}_{\mathrm{C}} \mathrm{U}_{\mathrm{L}} \mathrm{F}^{\prime} / \mathrm{mC}_{\mathrm{p}}\right)\right]
$$

For a particular case of a solar air heater without recycling and when inlet air temperature coincides the ambient (i.e., $t_{i=} t_{a}$ ), Eq. 7 reduces to $\eta=F_{R}(\tau \alpha)$ which results are efficacious due to various other parameters. In view of these limitations, Biondi et al. (1988) has proposed the following equation for efficiency of solar air heaters.

$$
\eta=F_{o}\left[(\tau \alpha)-U_{L}\left(\frac{t_{o}-t_{i}}{I}\right)\right]
$$

Where, $\mathrm{F}_{\mathrm{o}}$ is the heat removal factor referred to the outlet temperature and can be expressed as;

$$
\mathrm{F}_{\mathrm{O}}=\frac{\mathrm{GC}_{\mathrm{p}}}{\mathrm{U}_{\mathrm{L}}}\left[\operatorname{Exp}\left(\mathrm{U}_{\mathrm{L}} \mathrm{F}^{\prime} / \mathrm{GC}_{\mathrm{p}}\right)-1\right]
$$

Eq. 9 indicates that a plot of efficiency against $\left[\left(t_{o}-t_{i}\right) / I\right]$ will result in a straight line whose slope is $F_{o} U_{L}$ and ordinate axis intercept is $F_{o}(\tau \alpha)$, if $F_{o}, U_{L}$ and $(\tau \alpha)$ are not very strong functions of operating parameters like mass flow rate, intensity of solar radiation, ambient temperature and wind velocity variations. Further, thermal performance can also be expressed based on temperature gain produced by the collector and is expressed as; 


$$
\eta=\frac{\mathrm{GC}_{\mathrm{p}}\left(\mathrm{t}_{\mathrm{o}}-\mathrm{t}_{\mathrm{i}}\right)}{\mathrm{I}}
$$

\section{Results and Discussions}

Thermal performance of collectors roughened with multiple arcs with gap shaped geometry has been evaluated and presented. Fig. 4 shows the effect of thermal performance $\left(\eta_{t h}\right)$ with Reynolds number on relative roughness width $(W / w)$ for a fixed value of relative roughness height $(e / D)$ value of 0.045 , relative gap width $(g / e=1)$, arc angle $\left(\alpha=60^{\circ}\right)$, relative gap distance $(d / x)$ value of 0.65 and relative roughness pitch $(p / e=8)$. Variation of thermal performance, $\eta_{t h}$ of smooth collector with respect to Reynolds number has also been plotted to show the enhancement in thermal performance by providing multiple arcs with gap shaped roughness on the underside of the absorber plate.

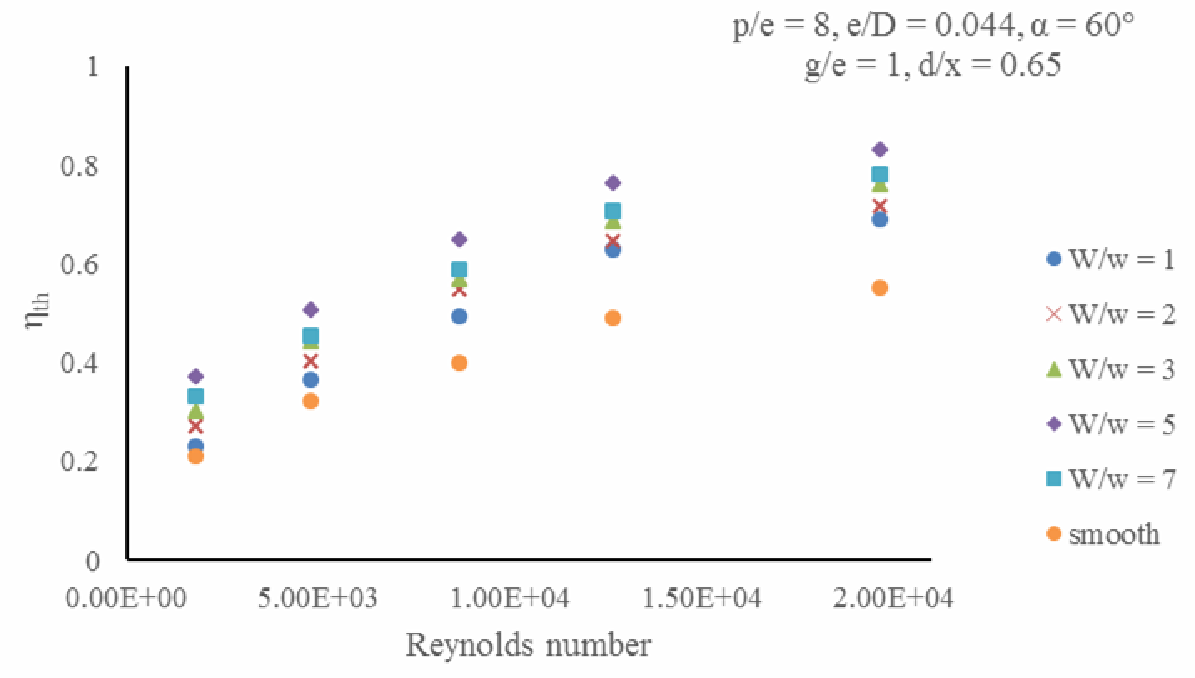

Fig. 4: Effect of thermal performance with Reynolds number for various values of $W / w$

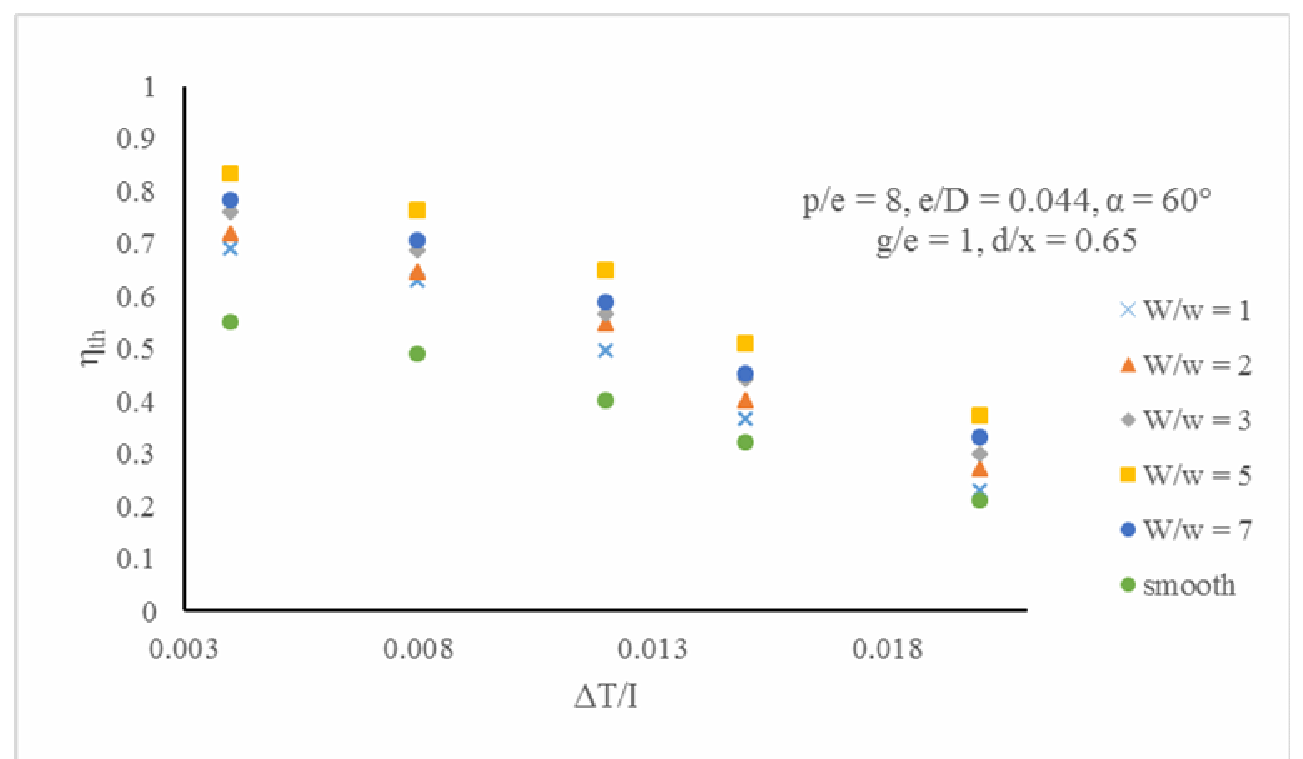

Fig. 5: Effect of thermal performance with temperature rise parameter for various values of $W / w$

It has been observed from the figure that the thermal efficiency of roughened collector is higher in comparison with that of smooth collector. The maximum thermal performance of roughened collector has been found to increase from 0.37 to 0.83 with an increase in Reynolds number from 2100 to 21000 for W/w value of 5. For smooth collector increase in thermal efficiency for Reynolds number has been found to be 0.21 to 0.55 . This can be explained that with the increase in $R e$, turbulence decreases which leads to increase in heat transfer. This figure also mentions that $\eta_{t h}$ increases with the increase in $W / w$ and attains a maximum value at $W / w$ of 5 . With further increase in W/w, $\eta_{t h}$ starts decreasing. This is due to the fact that angling of ribs helps in creating 
secondary flow and this flow promotes turbulence mixing and increase in $N u$ takes place. With the increase in number of arcs $(W / w)$, it would increase number of secondary flow which increases heat transfer. By further increase in arcs (beyond 5), it may result in the flow separation from top of rib surfaces hence reduction in heat transfer is noticed (Singh et al., 2014). Fig. 5 shows the variation of $\eta_{t h}$ with respect to temperature rise parameter $(\Delta T / I)$ for different values of relative roughness width. Result shows that with the increase in $\Delta T / I$ thermal performance decreases.

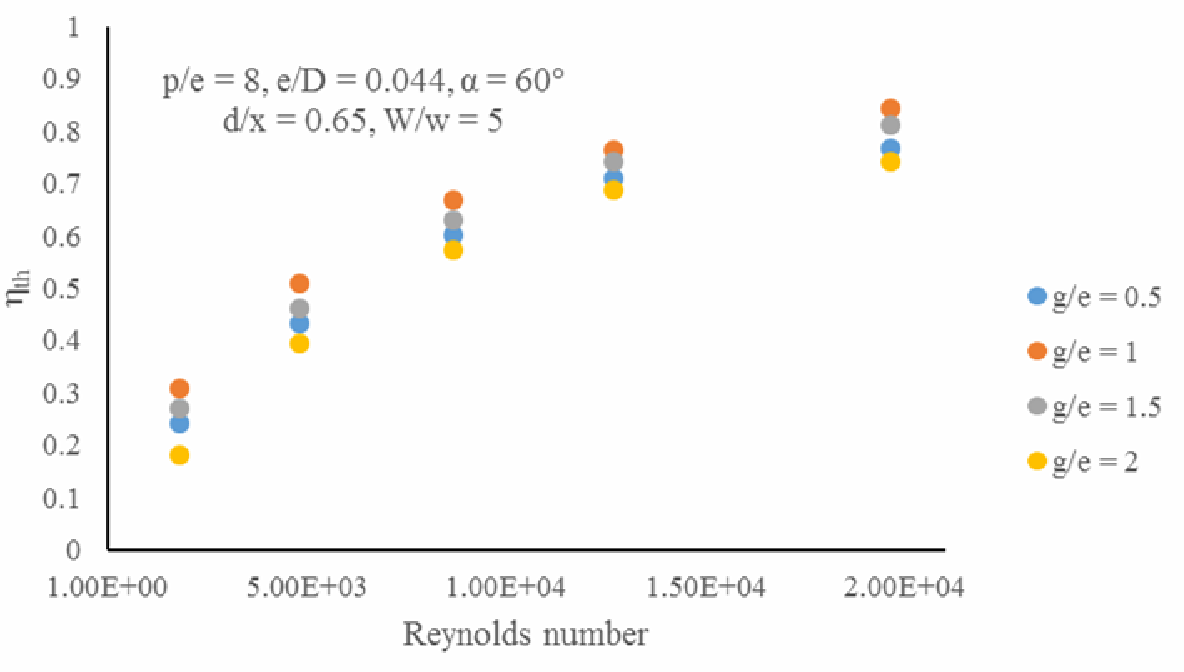

Fig. 6: Effect of thermal performance with Reynolds number for various values of $g / e$

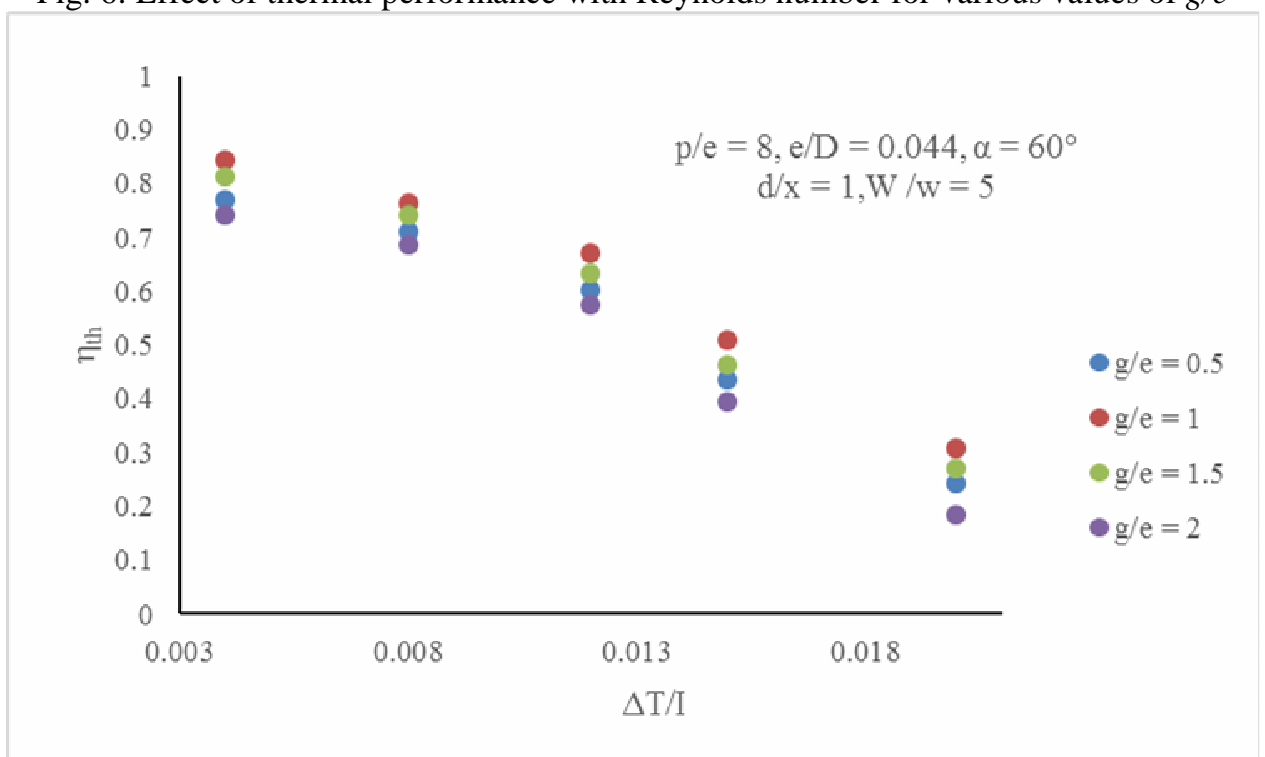

Fig. 7: Effect of thermal performance with temperature rise parameter for various values of $g / e$

Fig. 6 shows the effect of thermal performance $\left(\eta_{t h}\right)$ with Reynolds number on relative gap width $(g / e)$ for a fixed value of relative roughness height $(e / D)$ value of 0.045 , relative roughness width $(W / w=5)$, arc angle $\left(\alpha=60^{\circ}\right)$, relative gap distance $(d / x)$ value of 0.65 and relative roughness pitch $(p / e=8)$. This figure shows that $\eta_{t h}$ increases with the increase in upto g/e value of 1 , afterwards it start decreasing with the increase in $g / e$. The air passing through gap creates turbulence at downstream side. This change in $\eta_{t h}$ is due to gap which effects on air velocity passing through gap and also area disturbed by this flow (Singh et al., 2011). Larger the value of gap width, smaller is air velocity through gap and higher the downstream disturbance area. It appears that with the increase in $g / e$ beyond 1 , the flow velocity through gap will reduce and it is not strong to accelerate flow through gap. The effect of secondary flow on heat transfer is not significant. Therefore, increment in $\eta_{t h}$ not occur. Fig. 7 shows the variation of $\eta_{t h}$ with respect to temperature rise parameter $(\Delta T / I)$ for different values of relative gap width. Result shows that with the increase in $\Delta T / I$, thermal performance decreases due to decrease in mass flow (turbulence) rate of air.

Fig. 8 shows the effect of thermal efficiency $\left(\eta_{t h}\right)$ with Reynolds number on relative gap distance $(d / x)$ for a fixed value of relative roughness height $(e / D)$ value of 0.045 , relative roughness width $(W / w=5)$, arc angle $\left(\alpha=60^{\circ}\right)$, relative gap width $(g / e)$ value of 1 and relative roughness pitch $(p / e=8)$. It is evident from the figure that $\eta_{t h}$ increases with an increase in $d / x$ upto 0.65 
and after that it starts decreasing with further increase in $d / x$. This increase in $\eta_{\text {th }}$ is due to increase in flow mixing and turbulence resulting from accelerated flow through the gap. It is observed that if gaps were created near apex region, it helps in increasing local $\mathrm{Nu}$ which leads to increase in heat transfer and increase in $\eta_{t h}$ takes place. If the gaps are created too near to apex, two high local $\mathrm{Nu}$ region generated downstream of gap and region may overlap and no significant increase in $N u$ is observed and there is no increase in $\eta_{t h}$. Fig. 9 shows the variation of $\eta_{\text {th }}$ with respect to temperature rise parameter $(\Delta T / I)$ for different values of relative gap distance. Result shows that with the increase in $\Delta T / I$, thermal performance decreases due to decrease in mass flow (turbulence) rate of air and maximum performance is obtained for $d / x$ value of 0.65 .

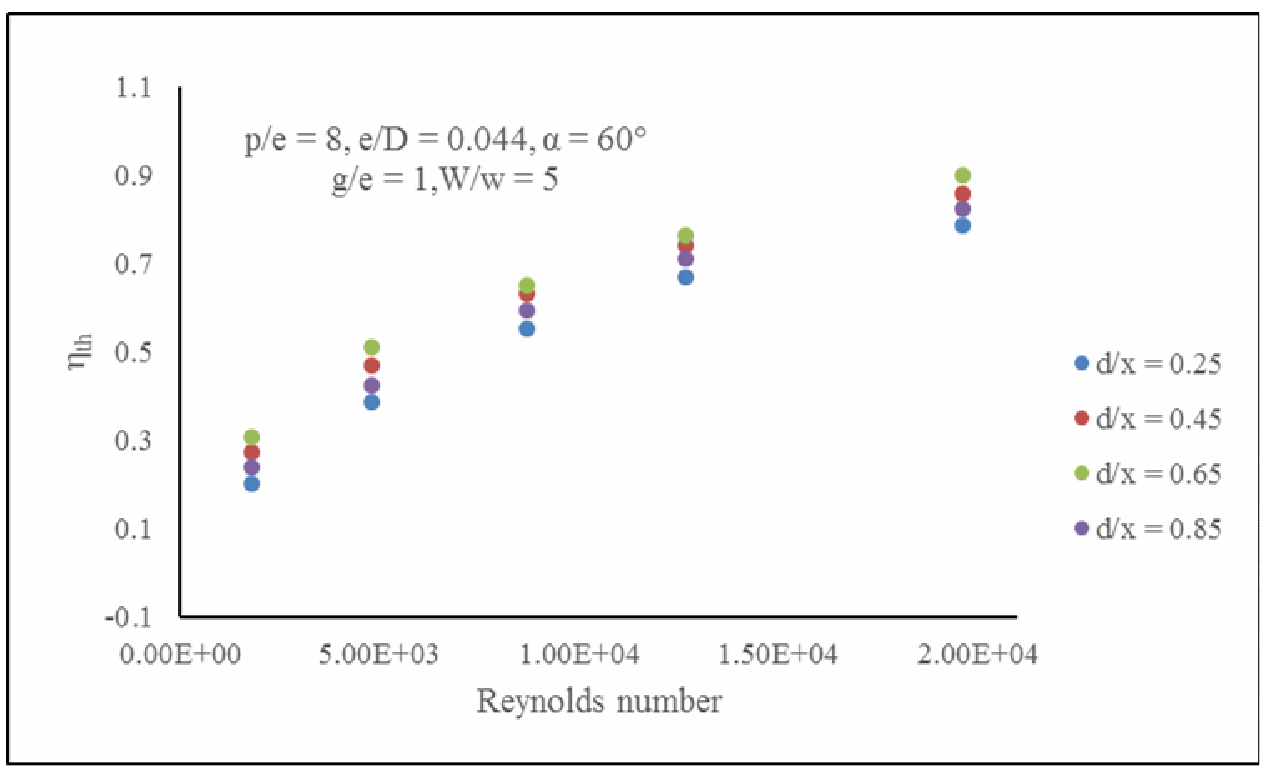

Fig. 8: Effect of thermal performance with Reynolds number for various values of $d / x$

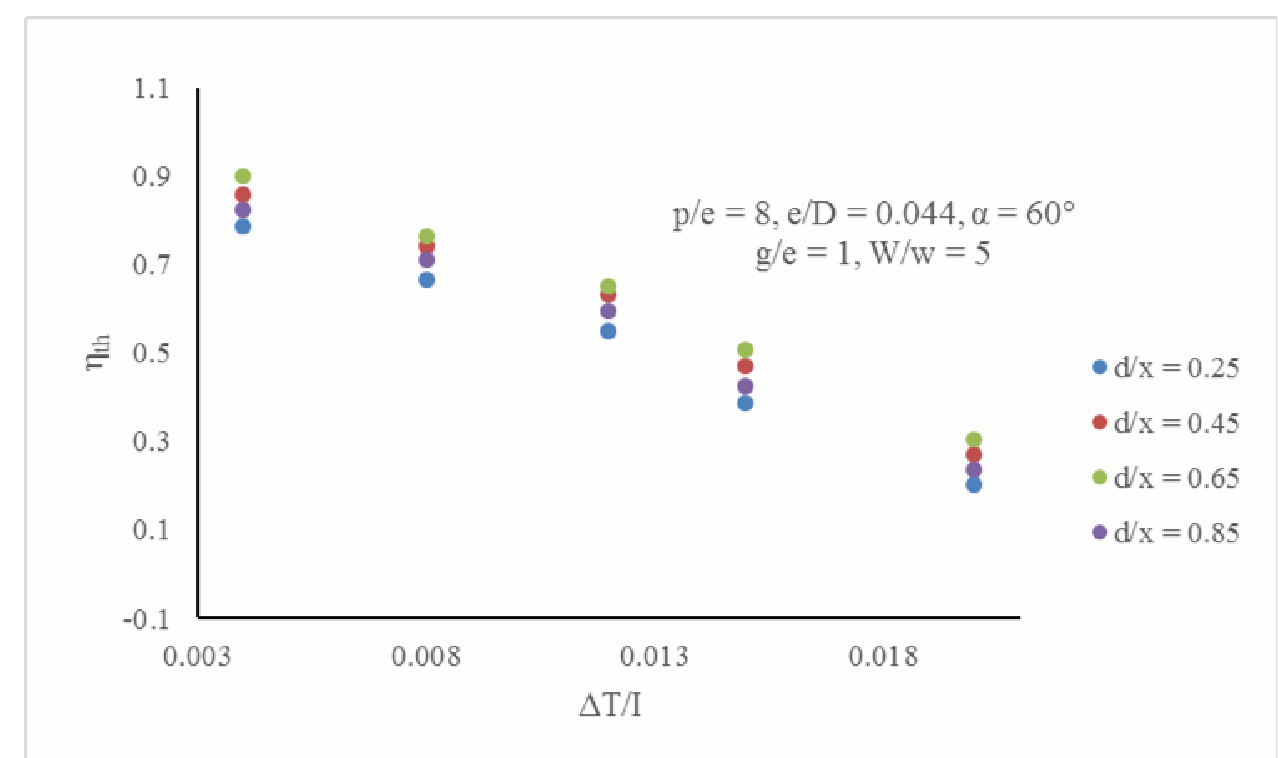

Fig. 9: Effect of thermal performance with temperature rise parameter for various values of $d / x$

CFD analysis were performed on different configurations of circular sectioned arc shaped ribs which are provided number of gaps on the absorber plate for values of Reynolds number. This accounts for different combinations of Reynolds number $(R e)$, roughness pitch $(p)$ and number of gaps $(\mathrm{Ng})$. CFD approach was used to predict Nusselt number $(\mathrm{Nu})$ and friction factor $(f)$. The thermo-physical properties of air are assumed to be at a temperature of $300 \mathrm{~K}$. The analysis is carried out using FVM (finite volume method) and the flow governing equations are discretized using second order upwind scheme. The SIMPLE (semi implicit method for pressure linked equations) algorithm is employed to estimate pressure-velocity coupled calculations. 


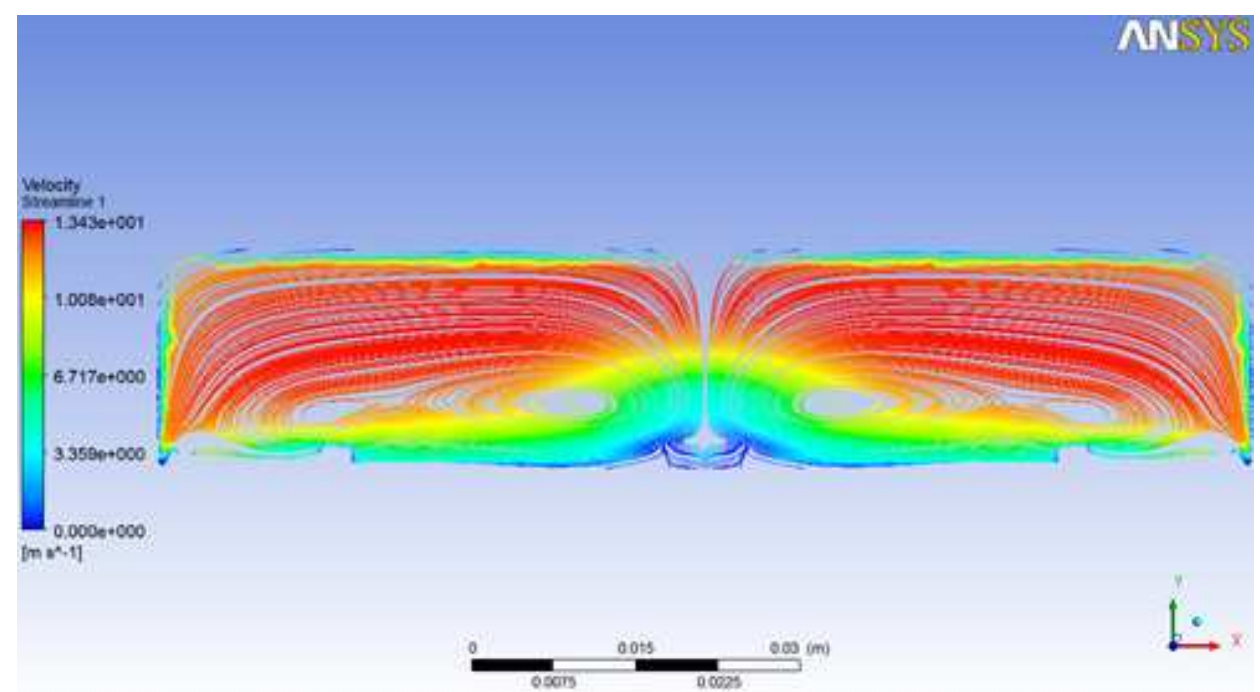

Fig. 10: Single gap at location $(z=0.3 \mathrm{~m})$ for $\mathrm{Re}$ at 20000 at $\mathrm{p} / \mathrm{e}$ of 8

\section{Conclusions}

In the present work, objective of detailed investigation was to see the effect of multiple arcs with gap shaped roughness elements on thermal performance of solar air heater. Results have also been compared with smooth duct. A significant enhancement in thermal performance has been obtained by using type of roughness on the absorber plate. The maximum value of $\eta_{t h}$ has been obtained for e/D, p/e, $\alpha, \mathrm{W} / \mathrm{w}, \mathrm{g} / \mathrm{e}$ and $\mathrm{d} / \mathrm{x}$ values of $0.045,8,60^{\circ}, 5,1$ and 0.65 respectively. The research finding may be used to increase the net heat input for various drying applications like seasoning of wood or room heating applications. The results shall be well suited to maximize the heat gained from solar energy. The research finding also presents a limitation that the user has to choose a roughness geometry depending upon several possible geometries available. The paper also does not discuss about the manufacturing aspect in context to absorber plates fitted with roughness geometries. Each type of geometry explored has its own functional aspect in context to advantages and disadvantages but the manufacturing considerations may be different.

\section{Nomenclature}

A Area $\left(\mathrm{m}^{2}\right)$

$C_{P} \quad$ Specific heat of air $(\mathrm{J} / \mathrm{kg}-\mathrm{K})$

$C_{d} \quad$ Coefficient of discharge

$D \quad$ Hydraulic diameter $(\mathrm{m})$

$e \quad$ Rib height (m)

$e / D \quad$ Relative roughness height

$\Delta h_{o} \quad$ Head difference in manometer (m)

$H \quad$ Height of duct (m)

$h \quad$ Heat transfer co-efficient $\left(\mathrm{W} / \mathrm{m}^{2}-\mathrm{K}\right)$

$k \quad$ Thermal conductivity $(\mathrm{W} / \mathrm{m}-\mathrm{K})$

$L \quad$ Test section length (m)

$m \quad$ Mass flow rate of air $(\mathrm{kg} / \mathrm{s})$

$\mathrm{Nu} \quad$ Nusselt number

$p \quad$ Pitch (m)

p/e Relative roughness height

$\mathrm{Pr} \quad$ Prandtl number

$Q_{u} \quad$ Useful heat gain (W)

Re Reynolds number

$t_{o} \quad$ Air outlet temperature (K)

$t \quad$ Temperature (K)

$\Delta \mathrm{T} / \mathrm{I} \quad$ Temperature rise parameter

$v \quad$ Mean flow velocity in duct $(\mathrm{m} / \mathrm{s})$

$W \quad$ Width of duct (m)

$W / w \quad$ Relative roughness width

\section{Greek Symbols}


$\begin{array}{ll}\alpha & \text { Arc angle }\left(^{\circ}\right) \\ \rho & \text { Density }\left(\mathrm{kg} / \mathrm{m}^{3}\right) \\ \beta & \text { Ratio of orifice diameter to pipe diameter }\end{array}$

\section{References}

Chamoli, S., 2013. Exergy analysis of a flat plate collector, Journal of Energy in Southern Africa, Vol. 24, No. 3, pp. 8-13.

Kumar, T.S., Thakur, N.S., Kumar, A., Mittal, V., 2010. Use of artificial roughness to enhance heat transfer in solar air heaters - a review, Journal of Energy in Southern Africa, Vol. 21, No. 1, pp. 35-51.

Varun, Saini, R.P., Singal, S.K., (2007), A Review on roughness geometry used in solar air heaters, Solar Energy, Vol. 81, pp. 1340-1350.

Prasad, B.N., Saini, J.S., 1988. Effect of artificial roughness on heat transfer and friction factor in solar air heater, Solar Energy, Vol. 41, pp. 555-560.

Varun, Saini, R.P., Singal, S.K., 2008. Investigation of thermal performance of solar air heater having roughness elements as a combination of inclined and transverse ribs on the absorber plate, Renewable Energy, Vol. 33, No. 6, pp. 1398-1405.

Biondi, P., Cicala, L., 1988. Farina G, Performance analysis of solar air heaters of conventional design, Solar Energy, Vol. 41, No. 1, pp. 101-107.

Bhagoria, J.L., Saini, J.S., Solanki, S.C., 2002. Heat transfer coefficient and friction factor correlations for rectangular solar air heater duct having transverse wedge shaped rib roughness on the absorber plate, Renewable Energy, Vol. 25, pp. 341-69

ASHRAE Standards 93-77, 1977. Methods of testing to determine the thermal performance of solar collectors. New York.

Singh, S., Chander, S., Saini, J.S., 2011. Heat transfer and friction factor correlations of solar air heater ducts artificially roughened with discrete V-down ribs, Energy, Vol. 36, pp. 5053-64.

Singh, A.P., Varun, Siddhartha, 2014. Effect of artificial roughness on heat transfer and friction characteristics having multiple arc shaped roughness element on the absorber plate, Solar Energy, Vol. 105, pp. 479-493.

Yadav, S., Kaushal, M., Varun, Siddhartha, 2013. Nusselt number and friction factor correlations for solar air heater duct having protrusions as roughness elements on absorber plate, Experimental Thermal Fluid Science, Vol. 44, pp. 34-41.

Kumar, A., Saini, R.P., Saini, J.S., 2013. Development of correlations for Nusselt number and friction factor for solar air heater with roughened duct having multi v-shaped with gap rib as artificial roughness, Renewable Energy, Vol. 58, pp. 151-163.

\section{Biographical notes}

Navneet Kumar Pandey is currently working with the Department of Mechanical Engineering, JSS Academy of Technical Education, Noida (UP) - 201301, India

V. K. Bajpai is working with the Department of Mechanical Engineering, National Institute of Technology Kurukshetra (Haryana), India

Received September 2015

Accepted November 2015

Final acceptance in revised form December 2015 